\section{Synthesis of Azabicyclo[3.1.1]heptane Derivatives from Cyclobutanones}

\section{Category}

Synthesis of

Heterocycles

\section{Key words}

azabicyclo[3.1.1] derivatives

cyclobutanones

pipecolic acid

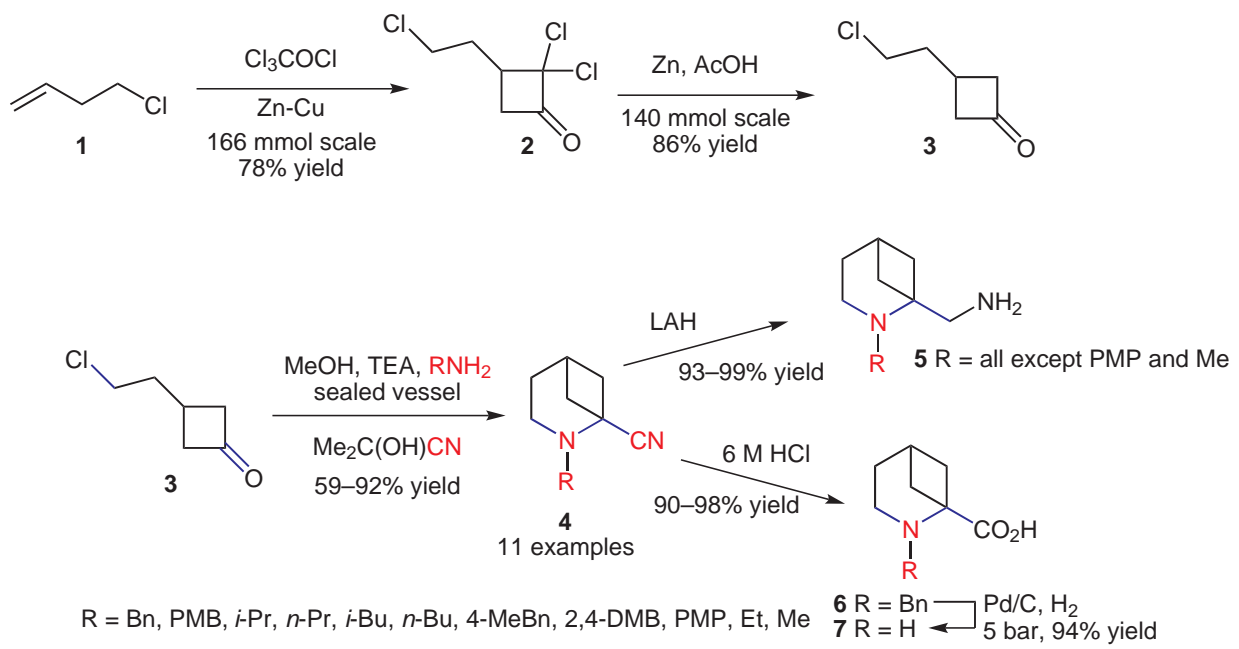

Significance: Reported is the synthesis of a variety of 2-alkyl-2-azabicyclo[3.1.1] heptane analogues $\mathbf{4}, \mathbf{5}$ and $\mathbf{7}$. This is only the second disclosure of the synthesis of these types of azabicyclic systems. Their incorporation into drug design programs may lead to compounds with novel biological properties due to the constrained nature of the ring system.
Comment: The syntheses of azabicyclo[3.1.1] derivatives of type $\mathbf{4}$ and $\mathbf{5}$ are not well represented in literature. The route utilizes a modification of the previously reported route described by Radchenko et al. (J. Org. Chem. 2009, 74, 5541). The key intermediate $\mathbf{3}$ was prepared on $>100 \mathrm{mmol}$ scale.

Furthermore, the current route provides access to compounds not previously described by Radchenko (R variation). 